\title{
ASPECTOS DA HISTÓRIA DO NÚMERO $\pi$ NA PERSPECTIVA DUMA FILOSOFIA DA MATEMÁTICA DE INSPIRAÇÃO WITTGENSTEINIANA
}

\author{
ASPECTS OF THE HISTORY OF NUMBER $\pi$ FROM THE PERSPECTIVE OF A PHILOSOPHY OF \\ MATHEMATICS INSPIRED BY THE LATER WITTGENSTEIN
}

Paulo Roberto Margutti Pinto*

\section{RESUMO}

No presente artigo, o autor tenta expor os princípios fundamentais duma filosofia da matemática que extrai sua inspiração do segundo Wittgenstein. Tais princípios são aplicados em seguida a dois momentos diferentes da história do número $\pi$. O objetivo é testar, ainda que de maneira superficial, a viabilidade dessa filosofia para a explicação pragmatista da objetividade e necessidade das proposições matemáticas.

PALAVRAS-CHAVE: Filosofia. Matemática. Wittgenstein. Número $\pi$.

\section{ABSTRACT}

In the current paper, the Author attempts to expose the basic principles concerning a philosophy of mathematics which takes its inspiration from the later Wittgenstein. Such principles are next applied to two different moments in the history of number $\pi$. The purpose is to test, although in a superficial way, the viability of such a philosophy for the pragmatist explanation of the objectivity and necessity of mathematical propositions.

KEYWORDS: Philosophy. Mathematics. Wittgenstein. $\pi$ number.

As coisas mais importantes em matemática são as que têm menos fundamento. É extraordinariamente surpreendente que a maior parte de tais coisas seja correta, apesar de tudo. Estou tentando achar uma razão para tal; é um problema muito interessante. (ABEL apud DANTZIG, 1970, p. 145).

\footnotetext{
* Doutor em Filosofia. Professor titular da UFMG e da Faculdade Jesuíta de Filosofia e Teologia (FAJE/MG). E-mail: pmargutti290@gmail.com.
}

Sapere aude - Belo Horizonte, v. 7 - n. 14, p. 605-626, Jul./Dez. 2016 - ISSN: 2177-6342 


\section{INTRODUÇÃO}

É inegável a ligação da matemática com a Filosofia. As relações entre ambas vêm das mais remotas origens da Filosofia Grega, cujos pensadores, como Tales e Pitágoras eram, ao mesmo tempo, filósofos e matemáticos. É conhecida a inscrição afixada à porta da Academia Platônica, proibindo a entrada de quem não fosse geômetra. E os debates sobre os Fundamentos da matemática envolvendo a questão do infinito acabam sempre remetendo às posições divergentes de Platão e Aristóteles a esse respeito. Desde seu aparecimento na civilização ocidental até os dias de hoje, as histórias dessas disciplinas se entrelaçam, e os avanços de uma repercutem na outra.

Mesmo assim, a discussão sobre os fundamentos das matemáticas é sempre renovada. Novas ideias surgem, novas concepções são elaboradas, os problemas passam a ser encarados sob nova luz. Nessa perspectiva, parecem-nos bastante fecundas as ideias sobre as matemáticas que foram introduzidas pelo filósofo contemporâneo Ludwig Wittgenstein (1889-1951), principalmente na segunda fase de seu pensamento. É verdade que a reconstituição da "filosofia da matemática" desse autor apresenta uma série de dificuldades. A interpretação de seus textos é arriscada, pois ele não publicou suas reflexões sobre o assunto, deixando-as sob a forma de anotações pessoais. Além disso, em certos momentos, aparenta estar completamente desatualizado quanto ao estado da pesquisa matemática posterior à década de vinte. Um outro problema está em que ele defendeu posições bastante radicais e fortemente restritivas, rejeitando domínios inteiros das matemáticas ${ }^{1}$.

Apesar dessas dificuldades, acreditamos ser possível extrair dos textos desse autor, se não uma "filosofia da matemática" completa, pelo menos algo que poderíamos denominar uma “concepção wittgensteiniana da matemática", cuja riqueza explicativa parece ser inegável. O objetivo do presente texto é estabelecer as bases mínimas para verificar a viabilidade dessa concepção, de modo a testá-la, ainda que superficialmente, através da análise de dois momentos importantes da história do número $\pi$.

Para efetuar essa tarefa, daremos os seguintes passos. Em primeiro lugar, com a finalidade de explicitar os princípios teóricos que dirigirão nossa análise, procuraremos indicar as teses mais

\footnotetext{
${ }^{1}$ Os domínios excluídos incluiriam a Teoria dos conjuntos, a Aritmética do infinito e a Metamatemática.
}

Sapere aude - Belo Horizonte, v. 7 - n. 14, p. 605-626, Jul./Dez. 2016 - ISSN: 2177-6342 
Artigo: Aspectos da história do número $\pi$ na perspectiva duma filosofia da matemática de inspiração wittgensteiniana

relevantes envolvidas pela "concepção wittgensteiniana da matemática". Em segundo lugar, mostraremos alguns dos principais aspectos da história do número $\pi$ na matemática grega, focalizando nossa atenção nos trabalhos de Arquimedes e interpretando-os de conformidade com a perspectiva proposta. Em terceiro lugar, passaremos para alguns dos resultados mais importantes que os matemáticos modernos alcançaram com relação ao mesmo número $\pi$, concentrando-nos agora na famosa "Fórmula de Euler". Aqui, também procuraremos interpretar tais resultados de acordo com a perspectiva que propomos, o que nos possibilitará também a comparação dos resultados de Arquimedes com os de Euler. Em quarto e último lugar, tentaremos extrair algumas das conclusões que o percurso acima sugere para a filosofia da matemática em geral. Gostaríamos de frisar que o presente estudo não é suficientemente detalhado para permitir conclusões definitivas, constituindo apenas um primeiro passo, no sentido de sugerir a possibilidade de realização de estudos mais completos. Em virtude disso, reconhecemos de antemão que as proposições e demonstrações matemáticas que perpassam o presente texto são simplificadas e carecem de rigor. Qualquer tentativa de reelaborá-las, obedecendo a critérios mais rígidos, contudo, poderia alterar mais ainda sua singularidade histórica e tornaria o texto excessivamente pesado ${ }^{2}$.

\section{PRINCIPAIS ASPECTOS DA “CONCEPÇÃO WITTGENSTEINIANA DA MATEMÁTICA”}

Conforme mencionado, o segundo Wittgenstein conseguiu elaborar uma filosofia bastante original no que diz respeito às matemáticas. $\mathrm{O}$ fato importante a ser destacado aqui é que ele as encara a partir duma perspectiva pragmatista, cujas características principais são duas. Em primeiro lugar, lado a lado com os intuicionistas e contra os matemáticos realistas, Wittgenstein defende a tese de que os teoremas matemáticos não são "descobertos" pelos seres humanos, mas sim construídos ou inventados por eles. Em outros termos, não há um "mundo ideal", composto por "entidades matemáticas", onde os seres humanos vão buscar as "relações ideais" entre tais "entidades". Os teoremas matemáticos são construídos a partir dos materiais disponíveis num dado momento histórico. Em segundo lugar, contra realistas e intuicionistas ao mesmo tempo, ele

\footnotetext{
${ }^{2}$ Convém lembrar que a nossa análise envolverá aspectos pertencentes a dois períodos históricos diferentes, cujos padrões de rigor são também diferentes.
}

Sapere aude - Belo Horizonte, v. 7 - n. 14, p. 605-626, Jul./Dez. 2016 - ISSN: 2177-6342 
afirma que as inferências matemáticas são contingentes, refletindo a maneira pela qual nossa cultura as concebe e. efetua. Nessa perspectiva, que confere à filosofia de Wittgenstein a originalidade que lhe é própria, os fundamentos da matemática não são epistemológicos ou metafísicos, mas devem ser buscados em nossa forma de vida particular.

Comentemos mais um pouco a segunda dessas teses pragmatistas, já que é através dela que a posição wittgensteiniana se torna original. De acordo com o matemático clássico e o intuicionista, as inferências matemáticas são necessárias. O primeiro justifica tal fato pela objetividade do mundo das entidades matemáticas que ele descobre. O segundo, pela objetividade dos processos demonstrativos que constrói. Em que pesem as diferenças determinadas pelas diferentes visões dos fundamentos da matemática, ambos consideram que a associação de axiomas com regras de inferência só pode levar à formulação de consequências necessárias. Quanto às regras de inferência, é exatamente a sua clareza e precisão que possibilita a formulação de tais consequências.

Conforme o Wittgenstein da segunda fase, as inferências matemáticas são contingentes. A crença na objetividade é uma superstição, e tanto o matemático clássico como o intuicionista são platônicos desse ponto de vista: o matemático clássico, de maneira declarada, por acreditar na objetividade dos entes matemáticos; o matemático intuicionista, de maneira velada, por acreditar na objetividade de suas demonstrações. Mas, se as inferências matemáticas são contingentes, como explica Wittgenstein aquelas proposições que denominamos 'necessárias'? A resposta é, ao mesmo tempo, simples e paradoxal: uma proposição necessária é aquela que não somente aceitamos sem questionamento, como também rejeitamos enfaticamente qualquer refutação que dela se tente fazer.

Nessa perspectiva, dizer que as inferências matemáticas são necessárias porque obedecem a regras formuladas de maneira precisa também constitui uma ilusão. Com efeito, por mais precisas e rigorosas, estas regras têm que ser elucidadas através da linguagem corrente, que é ambígua e imprecisa. Essa elucidação, por melhor que seja, deverá terminar em algum ponto. A partir desse ponto, haverá uma enorme diversidade de interpretações possíveis, colocando em xeque a precisão da regra.

Isso permite concluir que a matemática está sempre "em aberto", no que diz respeito à interpretação e criação de novas regras, principalmente quando se trata de resolver as questões

Sapere aude - Belo Horizonte, v. 7 - n. 14, p. 605-626, Jul./Dez. 2016 - ISSN: 2177-6342 
Artigo: Aspectos da história do número $\pi$ na perspectiva duma filosofia da matemática de inspiração wittgensteiniana

em pauta numa determinada época. Imaginemos que a série $1,2,3,4,5, \ldots$ fosse representativa do conhecimento matemático atual. Nesse caso, teremos de reconhecer que a sua continuação através da série $6,7,8,9,10 \ldots$ constitui apenas uma das possibilidades disponíveis. Há uma infinidade delas, como, por exemplo: a) 1, 2, 3, 4, 5, 1, 2, 3, 4, 5, 1, 2, 3, 4, 5,.. (regra: após o quinto número, repetir a sequência); b) $1,2,3,4,5,7,9,11,13,15,18,21,24,27,30, \ldots$ (regra: depois do quinto número, os próximos cinco números são obtidos acrescentando-se ' 2 ' ao anterior; os próximos cinco números são obtidos acrescentando-se '3' ao anterior; etc.); c) 1, 2, 3, $4,5,10,15,20,25,30,35, \ldots$ (regra: depois do quinto número, acrescentar sempre ' 5 ' ao anterior); etc. Assim, podemos dizer que a tese platonista, presente tanto no matemático clássico como no intuicionista, se baseia num círculo vicioso. Por um lado, ela considera que é o padrão adotado que garante a aplicação correta da regra. No caso das séries citadas, o padrão adotado pelas culturas ocidentais em geral é a sucessão dos números naturais. E a garantia de prosseguimento após chegarmos ao quinto número da sucessão é dada pelo mesmo padrão. Por outro lado, é a obediência à regra que garante o padrão adotado. Com efeito, o que garantiu o padrão adotado pelas culturas ocidentais para se chegar ao quinto número foi a aplicação continuada da mesma regra de adicionar mais um. Nos exemplos considerados acima, porém, esta regra foi alterada após atingirmos tal ponto, gerando-se três diferentes interpretações da regra, cujas aplicações levaram a três diferentes padrões ${ }^{3}$.

De acordo com Wittgenstein, é preciso escolher um padrão determinado para aplicar corretamente a regra. Uma proposição matemática, cujo cálculo não foi determinado por um padrão, não possui ainda sentido definido: este último só será determinado após a escolha do padrão. Entretanto, tal escolha é um fato contingente. Assim, em cada fase de uma prova, estamos decidindo sobre a correta aplicação da regra e, além disso, a aceitação de uma prova inovadora acarreta a aceitação de uma regra também inovadora, que é capaz de modificar nossos conceitos. Do mesmo modo que a escolha do padrão, a aceitação social da prova através do novo método é um fato contingente: poderá ocorrer ou não, conforme as exigências da prática social da época em que for proposta. Com isso, fica reiterada e reforçada a tese de que a fundamentação das matemáticas está num fato contingente e não numa necessidade objetiva que se imponha a nós do exterior.

3 É interessante observar que, para os britânicos, p. ex., um bilhão corresponde a um milhão de milhões (1.000.000.000.000), enquanto para nós, latinos, corresponde a mil milhões (1.000.000.000).

Sapere aude - Belo Horizonte, v. 7 - n. 14, p. 605-626, Jul./Dez. 2016 - ISSN: 2177-6342 
Como observamos anteriormente, a reconstituição da filosofia da matemática do segundo Wittgenstein envolve não apenas dificuldades de interpretação, como também uma concepção muito restritiva do domínio dessa disciplina. Dessa maneira, consideramos mais adequado adotar a distinção entre a "filosofia da matemática do segundo Wittgenstein" e uma "filosofia da matemática de orientação wittgensteiniana". A primeira expressão designa aquela filosofia que resulta da aceitação em bloco da perspectiva do segundo Wittgenstein. De acordo com ela, as matemáticas constituem um jogo ou, mais ainda, a gramática de um tipo específico de linguagem. Sua tarefa principal está na análise das regras dessa gramática. Desse ponto de vista, as matemáticas progridem por invenção, e suas inferências são contingentes. Ao lado disso, todavia, Wittgenstein também afirma que há, nas matemáticas, construções gramaticalmente equivocadas, como a teoria dos conjuntos. Quanto a isto, temos três observações a fazer. Em primeiro lugar, embora, por razões de espaço, não pretendamos discutir este ponto aqui, o certo é que não temos certeza se as críticas de Wittgenstein à teoria dos conjuntos e outros domínios das matemáticas são corretas. Sabemos, pelo menos, que seu desconhecimento dos avanços da lógica e da matemática a partir da década de vinte é notório. Em segundo lugar, não podemos negar o fato de que predomina um grande consenso entre os matemáticos, no que diz respeito à utilidade e validade desses mesmos domínios que Wittgenstein critica. Como bom pragmatista, ele deveria reconhecer tal consenso de maneira mais positiva. Em terceiro, embora não pretendamos discutir esse ponto aqui, por razões de espaço, não nos parece que as críticas feitas por Wittgenstein à teoria dos conjuntos e a outros domínios da matemática constituam uma decorrência de suas teses filosóficas principais sobre a natureza da própria matemática. Assim, achamos mais prudente não adotar em sua totalidade a filosofia de Wittgenstein relativa às matemáticas. Preferimos optar por aquilo que denominamos uma "filosofia da matemática de inspiração wittgensteiniana". Com esta expressão, entendemos aquela filosofia que se inspira no segundo Wittgenstein, sem, contudo, com ele identificar-se plenamente. De acordo com essa maneira de ver as coisas, aceitaremos as ideias de invenção e contingência nas matemáticas, recusando, entretanto, em franca contradição com Wittgenstein, as rígidas limitações gramaticais que ele impôs. Diante do consenso contemporâneo quanto à aceitação dos domínios por ele recusados, deixaremos em aberto a possibilidade da construção de gramáticas compatíveis com tais domínios. Esse tipo de atitude com respeito à filosofia da matemática de Wittgenstein não constitui novidade (BLOOR, 1973;

Sapere aude - Belo Horizonte, v. 7 - n. 14, p. 605-626, Jul./Dez. 2016 - ISSN: 2177-6342 
Artigo: Aspectos da história do número $\pi$ na perspectiva duma filosofia da matemática de inspiração wittgensteiniana

STEGMÜLLER, 1977, P. 508-524) e parece-nos perfeitamente exequível, não envolvendo, à primeira vista, qualquer inconsistência. Consideramos que o poder explicativo e a "tolerância epistemológica" de uma concepção obtida a partir da atitude mencionada são muito maiores. Nesta primeira abordagem do assunto, porém, não pretendemos justificá-la aprioristicamente. Consideramos que a melhor maneira de tornar clara a concepção que adotamos é testar seu potencial de explicação na análise de casos concretos. Para tanto, escolhemos dois momentos da história do famoso número ' $\pi$ '. Assim, o prosseguimento de nossa análise se fará no contexto de uma filosofia da matemática de inspiração wittgensteiniana que deixa de lado algumas das teses mais radicais do pensador austríaco. Wittgenstein, com toda sua obsessão pelo rigor, certamente torceria o nariz diante dessa atitude, mas não faz mal.

\section{ASPECTOS DA HISTÓRIA DO NÚMERO ‘ $\pi$ ’ NA MATEMÁTICA GREGA}

O primeiro dos momentos mencionados se refere ao cálculo feito por Arquimedes da razão entre o perímetro da circunferência e seu diâmetro. Para efetuarmos esta discussão, devem ser feitas, entretanto, algumas observações preliminares, a guisa de introdução.

A matemática praticada pelos gregos tem a característica especial de ser toda voltada para a geometria. Com efeito, diversos problemas hoje considerados algébricos eram enfocados numa perspectiva geométrica. Assim, elevar um número ao quadrado para eles equivalia a construir um quadrado cujo lado tivesse aquele número como medida. Elevar um número ao cubo era equivalente a construir um cubo cuja aresta tivesse aquele número como medida. As próprias expressões atuais, como "quadrado" e "cubo", só têm sentido enquanto remanescentes da tradição grega.

Ora, dentre os problemas geométricos que preocupavam os gregos estava o da "quadratura do círculo". Tratava-se de construir um quadrado cuja área fosse equivalente à de um círculo dado, com o auxílio exclusivo de régua e compasso. Em seu livro Medida do círculo, Arquimedes (apud CAJORI, 1919, p. 34) consegue provar que a área do círculo é equivalente à área de um triângulo cuja base é o perímetro da circunferência e cuja altura é o raio (Figura 1).

Sapere aude - Belo Horizonte, v. 7 - n. 14, p. 605-626, Jul./Dez. 2016 - ISSN: 2177-6342 


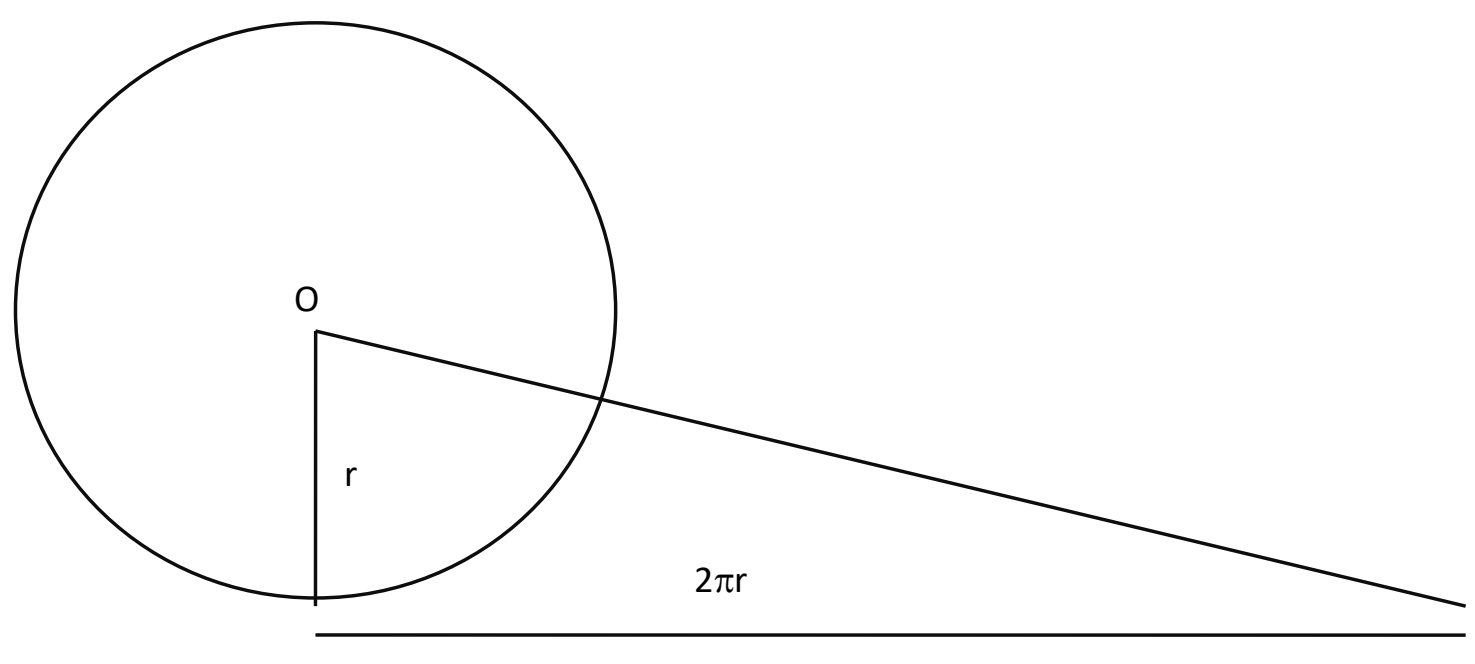

A

Figura 1. A área do círculo de centro $\mathrm{O}$ é igual à área do triângulo $\mathrm{OAB}$. Em termos atuais, teríamos: Área do círculo de centro $\mathrm{O}=\pi \mathrm{r}^{2}$ Área do triângulo $\mathrm{OAB}=(\mathrm{AB} \times \mathrm{OA}) / 2=(2 \pi \mathrm{r} \times \mathrm{r}) / 2=\pi \mathrm{r}^{2}$

Para determinar a área do círculo, torna-se crucial que Arquimedes conheça a razão entre a circunferência e o diâmetro, pois, de acordo com sua perspectiva, o conhecimento dela possibilitará obter o perímetro a partir do raio. A fim de calculá-la, Arquimedes recorre a um método inteiramente revolucionário para sua época: o da exaustão. Esse método consiste no seguinte. Em primeiro lugar, ele circunscreve um triângulo equilátero ao círculo e começa a dobrar indefinidamente o número de seus lados, obtendo, pela ordem, polígonos regulares circunscritos de 6,12, 24, 48 e 96 lados. Através desse procedimento, é possível construir polígonos regulares cujos contornos se aproximam cada vez mais, por fora, do contorno do próprio círculo. Quanto maior o número de lados do polígono, tanto mais próximos estaremos do contorno do círculo. O polígono de 96 lados quase que já se confunde com o próprio círculo. Isso permite concluir que os perímetros dos diversos polígonos regulares que envolvem o círculo tendem para um limite, que é exatamente o perímetro do círculo. O perímetro do polígono de 48 lados é menor do que o do polígono de 24 lados; o perímetro do de 96 lados é menor do que o do polígono de 48 lados; e assim sucessivamente. Quanto maior é o número de lados do polígono regular circunscrito, tanto menor é o seu perímetro com relação aos polígonos regulares 
Artigo: Aspectos da história do número $\pi$ na perspectiva duma filosofia da matemática de inspiração wittgensteiniana

circunscritos de menor número de lados. Mesmo assim, todos estes perímetros serão maiores do que o perímetro do círculo, que constitui o limite para o qual os perímetros de todos estes polígonos tendem. Como se pode ver, o cálculo dos diversos perímetros dos polígonos regulares circunscritos, que era perfeitamente factível na época de Arquimedes, permite que encontremos o valor que constitui o limite para o qual eles tendem, valor este que, embora seja ligeiramente superior ao perímetro do círculo, praticamente se confunde com este último. Em outras palavras, o perímetro do polígono regular de 96 lados, embora seja ligeiramente maior do que o perímetro do círculo inscrito, praticamente se confunde com ele. Nesse caso, para calcular a razão entre a circunferência e o diâmetro do círculo, Arquimedes divide o perímetro do polígono regular de 96 lados pelo diâmetro do círculo, obtendo assim para $\pi$ um valor que ele sabe ser ligeiramente inferior à fração 3 10/70.

Em segundo lugar, ele inscreve um triângulo equilátero no mesmo círculo e dobra sucessivamente os seus lados, obtendo, também pela ordem, polígonos regulares inscritos de 6,12, 24, 48 e 96 lados. Assim agindo, Arquimedes consegue construir polígonos regulares cujos contornos se aproximam cada vez mais, agora por dentro, do contorno do próprio círculo. Quanto maior o número de lados do polígono inscrito, tanto mais próximos estaremos do contorno do círculo. Do mesmo modo que no caso anterior, o polígono inscrito de 96 lados quase já se confunde com o próprio círculo. Isso permite concluir que os perímetros dos diversos polígonos regulares inscritos no círculo tendem para um limite, que é exatamente o perímetro do círculo. Aqui, o perímetro do polígono de 48 lados é maior do que o do polígono de 24 lados; o perímetro do de 96 lados é maior do que o do polígono de 48 lados; e assim sucessivamente. Quanto maior é o número de lados do polígono regular inscrito, tanto maior é o seu perímetro com relação aos polígonos regulares inscritos de menor número de lados. Mesmo assim, cada um desses perímetros será menor do que o perímetro do círculo, que constitui o limite para o qual os perímetros de todos estes polígonos tendem. Como se pode ver, o cálculo dos diversos perímetros dos polígonos regulares inscritos, que também era perfeitamente factível na época de Arquimedes, permite que encontremos o valor que constitui o limite para o qual eles tendem, valor este que, embora seja agora ligeiramente inferior ao perímetro do círculo, praticamente se confunde com este último. Isto quer dizer que, p. ex., o perímetro do polígono regular de 96 lados, embora seja ligeiramente menor do que o perímetro do círculo circunscrito, praticamente

Sapere aude - Belo Horizonte, v. 7 - n. 14, p. 605-626, Jul./Dez. 2016 - ISSN: 2177-6342 
se confunde com ele. Neste caso, para calcular a razão aproximada entre a circunferência e o diâmetro do círculo, Arquimedes divide o perímetro do polígono regular de 96 lados pelo diâmetro do círculo, obtendo assim para $\pi$ um valor que ele sabe ser ligeiramente superior à fração 3 10/71. Assim, embora não tenha calculado exatamente o valor de $\pi$, Arquimedes consegue mostrar que tal valor está entre $310 / 70$ e 3 10/71, o que constitui uma excelente aproximação (CAJORI, 1919, p. 35). O procedimento descrito acima é suficientemente rico para permitir constatar também que a área do círculo é o limite para os quais tendem as áreas dos polígonos regulares inscritos e circunscritos, quando o número de lados deles cresce indefinidamente. Que Arquimedes tenha levado seus cálculos apenas até o polígono de 96 lados é um fato absolutamente contingente que não poderemos explicar a não ser através de extrapolações.

Do ponto de vista da concepção wittgensteiniana da matemática, a atitude de Arquimedes envolve a reinterpretação de uma regra. De fato, ele não calcula as dimensões do círculo, como a sua área ou seu perímetro, da mesma forma que o faz para um quadrado ou um triângulo. Através de seu método, ele chega por aproximação: seu raciocínio se baseia na possibilidade de retificar uma curva. Ora, assim agindo, Arquimedes dá um sentido inteiramente novo aos conceitos de "área", "perímetro" e "círculo". Enquanto figura geométrica, este último passa a ser considerado o limite para o qual tendem os polígonos regulares inscrito e circunscrito, quando o número de lados de ambos cresce indefinidamente. Isso envolve a consideração de quantidades infinitamente pequenas ou infinitésimos. Mesmo assim, o siracusano tem uma visão inteiramente helênica do infinitésimo. Muito provavelmente influenciado pelos paradoxos de Zenão, Arquimedes compartilha com seus coetâneos aquilo que Tobias Dantzig denominou o "horror infiniti": "o infinito era tabu, tinha que ser mantido de fora a qualquer custo, ou então, não se conseguindo isso, devia ser camuflado por argumentos absurdos e semelhantes" (DANTZIG, 1970, p. 119). Isso leva Arquimedes a adotar uma atitude ambígua face ao infinito: ele o usa em suas pesquisas exploratórias, que podem, no máximo, sugerir relações matemáticas importantes; mas ele o exclui radicalmente das demonstrações consideradas rigorosas.

Quanto à natureza do próprio número $\pi$ (que nenhum grego representou por essa letra), tudo leva a crer que o siracusano o considerava racional, mesmo que seu valor exato ainda não tivesse sido encontrado. Afinal de contas, ele era definido como a razão da circunferência para o 
Artigo: Aspectos da história do número $\pi$ na perspectiva duma filosofia da matemática de inspiração wittgensteiniana

diâmetro, e Proclos já dizia: "conta-se que os primeiros que tiraram os irracionais do segredo e os levaram a público pereceram num naufrágio. Pois o inexprimível e o sem-forma deve ser escondido. $\mathrm{E}$ os que descobriram e trocaram essa imagem da vida foram instantaneamente destruídos e permanecerão para sempre expostos às ondas eternas" (apud DANTZIG, 1970, p. 97-98). De acordo com a concepção wittgensteiniana da matemática, podemos reavaliar a situação como segue. Embora a suposição de que o número $\pi$ é racional tenha sido reforçada pelo apelo ao método arquimediano da exaustão, que lhe dá um valor aparentemente racional entre as frações 3 10/70 e 3 10/71, tal resultado foi obtido através dum procedimento de aproximação no mínimo controverso entre os gregos, procedimento este que o próprio Arquimedes excluía do domínio das demonstrações rigorosas. Desse modo, a inexistência de um método considerado rigoroso para calcular o número $\pi$ torna o problema de saber se ele é racional ou não desprovido de sentido determinado nessa fase de sua história.

\section{ASPECTOS DA HISTÓRIA DO NÚMERO ‘ $\pi$ ’ NA MATEMÁTICA MODERNA}

Durante aproximadamente dezoito séculos após a introdução do método de Arquimedes, os progressos no problema da determinação do valor e da natureza de $\pi$ foram praticamente nulos. Mesmo assim, a legião dos quadratores de círculos sempre esteve presente, contribuindo com sugestões matemáticas interessantes. Foi somente na segunda metade do século XVIII que o problema adquiriu nova roupagem. Primeiramente, o matemático Euler (1707 - 1783), além de introduzir o símbolo ' $\pi$ ' para o nosso número, chegou a uma importante relação em 1748 (CAJORI, 1919, p. 236; DUBREIL, 1948, p. 110). Seu ponto de partida foram as seguintes séries infinitas ${ }^{4}$ :

(2) $\mathrm{e}^{\mathrm{x}}=1+\mathrm{x} / 1 !+\mathrm{x}^{2} / 2 !+\mathrm{x}^{3} / 3 !+\mathrm{x}^{4} / 4 !+\ldots$

(3) $\cos \varphi=1-\varphi^{2} / 2 !+\varphi^{4} / 4 !-\varphi^{6} / 6 !+\ldots$

(4) $\operatorname{sen} \varphi=\varphi / 1 !-\varphi^{3} / 3 !+\varphi^{5} / 5 !-\varphi^{7} / 7 !+\ldots$

Nelas, ' $x$ ' representa um número qualquer e ' $\varphi$ ', um ângulo medido em radianos. Fazendo $x=i \varphi$ na relação (2), obtemos:

\footnotetext{
${ }^{4}$ A passagem das relações (2), (3) e (4) para (7) e (8) é nossa, mas parece-nos que Euler a faria do mesmo modo.
}

Sapere aude - Belo Horizonte, v. 7 - n. 14, p. 605-626, Jul./Dez. 2016 - ISSN: 2177-6342 
$\left(2^{\prime}\right) \mathrm{e}^{\mathrm{i} \varphi}=1+\mathrm{i} \varphi / 1 !-\varphi^{2} / 2 !-\mathrm{i} \varphi^{3} / 3 !+\varphi^{4} / 4 !+i \varphi^{5} / 5 !-\varphi^{6} / 6 !-\mathrm{i} \varphi^{7} / 7 !+\ldots$

Multiplicando sen $\varphi$ por i na relação (4), temos:

(5) isen $\varphi=i \varphi / 1 !-i \varphi^{3} / 3 !+i \varphi^{5} / 5 !-i \varphi^{7} / 7 !+\ldots$

Adicionando agora as relações (3) e (5) membro a membro, de modo a tomar primeiro um termo de (3) e depois, um termo de (5), obtemos:

(6) $\cos \varphi+i \operatorname{sen} \varphi=1+i \varphi / 1$ ! - $\varphi^{2} / 2 !-i \varphi^{3} / 3 !+\varphi^{4} / 4 !+i \varphi^{5} / 5 !-\varphi^{6} / 6 !-i \varphi^{7} / 7 !+\ldots$

As relações (2') e (6) têm idêntico segundo termo, fato que nos permite escrever:

(7) $\mathrm{e}^{\mathrm{i} \varphi}=\cos \varphi+\mathrm{isen} \varphi$

Esta é a famosa "Fórmula de Euler", em que, fazendo $\varphi=\pi$, teremos: $\cos \pi=-1$ e sen $\pi=$ 0 . Portanto,

(8) $\mathrm{e}^{\mathrm{i} \pi}=-1$

$$
\text { ou } \quad \mathrm{e}^{\mathrm{i} \pi}+1=0
$$

A identidade acima é uma das mais belas da História das matemáticas. Para alguns dos contemporâneos de Euler, ela possuía um verdadeiro significado de união mística da Aritmética (representada por ' 1 ' e ' 0 ' ), da Álgebra (representada por 'i'), da Geometria (representada por ' $\pi$ ') e da Análise (representada pelo número 'e').

Alguns anos depois, em 1761, Lambert (1728 - 1777) provou que se x é um número racional diferente de zero, então tg x não pode ser racional. Ora, como tg $\pi / 4=1$ e 1 é racional e diferente de zero, segue-se que $\pi / 4$ é irracional. Neste caso, $\pi$ também deve sê-lo, com maior razão ainda (CAJORI, 1919, p. 246). Já em 1775, antes da obtenção de qualquer prova concreta desse fato, a Academia de Paris aprovou uma resolução oficial: não mais examinaria tentativas de solução do problema da quadratura do círculo (BOYER, 1974, p. 340). Isso não significava, contudo, que Lambert tivesse resolvido definitivamente a questão. Realmente, se $\pi$ é irracional, isso não quer dizer que não seja raiz de uma equação quadrática. Só neste último caso a quadratura do círculo com régua e compasso seria impossível. Havia, na verdade, uma forte tendência no sentido de considerá-la impossível, diante do espantoso número de quadratores que constantemente apresentavam suas soluções para apreciação da Academia. Prova dessa tendência é a afirmação de Legendre em 1794, relativa à possibilidade de $\pi$ não ser a raiz de uma equação

Sapere aude - Belo Horizonte, v. 7 - n. 14, p. 605-626, Jul./Dez. 2016 - ISSN: 2177-6342 
Artigo: Aspectos da história do número $\pi$ na perspectiva duma filosofia da matemática de inspiração wittgensteiniana

algébrica de número finito de termos e com coeficientes racionais, ou seja, de $\pi$ não ser um número algébrico (CAJORI, 1919, p. 268).

Para resolver o problema, era necessário exatamente esse avanço na teoria dos números. Os racionais, por exemplo, são raízes de equações lineares da forma $a x+b=0$, onde $x=-b / a$. Muitos irracionais podem ser raízes de equações quadráticas da forma $\mathrm{ax}^{2}+\mathrm{bx}+\mathrm{c}=0$, em que $\mathrm{a}$, b, e c são inteiros. Outros irracionais podem ser obtidos a partir da equação da forma $a x^{n}+b^{n-1}$ $+\mathrm{cx}^{\mathrm{n}-2}+\ldots+\mathrm{px}+\mathrm{q}=0$, em que $\mathrm{n}$ é maior que $2 \mathrm{e} \mathrm{a}, \mathrm{b}, \mathrm{c}, \ldots . \mathrm{p}$, q são inteiros. Esta última equação pode ser considerada a forma geral, a que as anteriores se reduzem. As raízes de todas essas equações podem ser definidas como números algébricos. Ora, como todo número racional é raiz da equação geral com $n=1$, coloca-se a pergunta de saber se todo irracional é raiz da equação geral quando $n>2$. Em 1844, Liouville construiu uma série de números não algébricos, também chamados transcendentes (BOYER, 1974, p. 406). Foi somente depois da proposta de Liouville que Charles Hermite, em 1873, demonstrou que é transcendente o número 'e’ (BOYER, 1974, p. 407). Nove anos depois, 1882, Lindemann, num artigo intitulado "Sobre o número $\pi$ ", conseguiu demonstrar que a razão da circunferência para o diâmetro também é transcendente. Em linhas gerais, a demonstração de Lindemann mostra que, quanto x é algébrico, x não pode satisfazer à equação

$(8) e^{i x}+1=0$.

Como, de acordo com Euler, $\pi$ satisfaz à referida equação, $\pi$ não pode ser algébrico (BOYER, 1974, p. 407). Agora sim, estava resolvida a questão da quadratura do círculo: para que ela fosse possível com o uso da régua e do compasso (os instrumentos euclidianos), $\pi$ teria necessariamente que ser algébrico, isto é, teria que ser raiz de uma equação algébrica cuja raiz pudesse ser expressa através de raízes quadradas. Sendo $\pi$ transcendente, "o círculo não pode ser quadrado segundo as regras clássicas" (BOYER, 1974, p. 408).

O que podemos dizer aqui, do ponto de vista duma filosofia da matemática de orientação wittgensteiniana? Comparando o método de exaustão de Arquimedes com os novos métodos empregados por Euler e seus sucessores, vemos que o número $\pi$ foi sendo gradativamente afastado de sua origem geométrica para transformar-se num instrumento de grande utilidade na Análise Matemática. Para que isso acontecesse, contudo, foi necessária uma reinterpretação das 
regras da Matemática Grega, aceitando-se que os infinitésimos pudessem compor demonstrações rigorosas. A legalização dos processos infinitesimais constitui a base da teoria das séries, através das quais foi possível calcular o número 'e'. Além disso, a criação de um certo tipo de trigonometria, associada à da medição dos ângulos em radianos, facilitou grandemente a passagem da geometria à álgebra. Mais ainda: a aceitação da possibilidade de calcular com raízes quadradas de números negativos nos leva a $\sqrt{-1}$ ou ' $i$ ' e à estruturação da teoria sobre os números complexos. De posse de todos esses métodos inovadores, foi possível aos Modernos estabelecer um novo tratamento do número $\pi$, agora irracional e transcendente. 'Irracional', contudo, em virtude das novas definições em jogo, já não significa exatamente a mesma coisa que significava para os gregos. 'Transcendente' constitui, sem dúvida, uma inovação. Tudo isso, de acordo com a concepção wittgensteiniana da matemática, só foi possível porque a introdução dos novos métodos citados permitiu decidir certas questões que permaneciam sem resposta. Não obstante, a introdução desses métodos alterou o sentido originário dos conceitos e mudou as regras do jogo, reinterpretando-as.

Para ilustrar a diferença profunda que existe entre a matemática grega e a moderna, retornemos à fórmula de Euler:

$$
\mathrm{e}^{\mathrm{i} \pi}+1=0
$$

Teriam os gregos condições de efetuar as operações nela indicadas? Somar, aqui, não é a mesma coisa que somar dois e dois. Elevar à potência $\pi$ não é o mesmo que elevar ao quadrado. Multiplicar i por $\pi$ definitivamente não é idêntico a multiplicar dois por dois. O próprio número $\pi$ não é mais apenas a razão da circunferência para o diâmetro, tendo sido radicalmente alterado em seu conceito. Estamos diante de outro conjunto de regras sociais relativas às operações matemáticas, um conjunto que difere essencialmente dos anteriores. Isso parece indicar que a aplicação de uma fórmula matemática constitui acima de tudo um processo social.

Vimos que a fórmula de Euler se baseia na relação (7):

$$
\mathrm{e}^{\mathrm{i} \varphi}=\cos \varphi+i \operatorname{sen} \varphi \text {. }
$$

Para chegar até ela, foram necessárias a adoção e a aceitação social, por parte dos modernos, de vários procedimentos eminentemente heterodoxos com respeito às regras 
Artigo: Aspectos da história do número $\pi$ na perspectiva duma filosofia da matemática de inspiração wittgensteiniana

anteriormente em voga entre os gregos, tais como: a) efetuar operações com séries infinitas (condição básica); b) aceitar que i ou $\sqrt{-1}$, uma grandeza absolutamente contraditória do ponto de vista da operação de extrair a raiz quadrada, se comporte como um número; c) aceitar regras precisas para operar com $i$ (na potenciação, por exemplo, $i^{1}=i, i^{2}=-1, i^{3}=-i$ e $i^{4}=1$ ); $d$ ) transitar da geometria para a álgebra através de diversas pontes (entre elas, a trigonometria). Em que pese o caráter heterodoxo desses procedimentos, a aceitação social deles parece contribuir para a sensação de que se "descobriu" alguma coisa, de que se obteve um esclarecimento maior sobre uma questão que permaneceu identicamente a mesma de Arquimedes até Euler. Daí se segue automaticamente o sentimento de que estamos caminhando em direção a um fim, que "A" matemática é uma só e tem sua própria teleologia: a explicitação das verdades eternas do mundo transceleste das entidades e relações matemáticas. Do ponto de vista em que nos colocamos, porém, isso parece constituir apenas uma ilusão.

\section{OBSERVAÇÕES FINAIS}

Se a interpretação acima sugerida para a história do número $\pi$ está correta, então devemos reformular a concepção tradicional, platônica, a respeito da necessidade e objetividade das inferências matemáticas. É verdade que, ao efetuá-las, somos, de fato, compelidos a chegar a uma dada consequência. Mas temos também de reconhecer que não é absolutamente necessário que a ela cheguemos: nós apenas chegamos - e isso é o que conta. Como diz o próprio Wittgenstein (1956, I, 7): "não, não é verdade que é necessário - mas segue-se: nós executamos essa transição". A necessidade matemática não obriga "de fora", a partir duma realidade objetiva exterior a nós, mas sim por convenção, por consenso do grupo social. As inferências que fazemos não são inexoráveis: nós é que somos. "A matemática forma como uma rede de normas", acrescenta Wittgenstein (p. 194). Ela funciona, portanto, como uma verdadeira instituição, já que constitui uma estrutura de práticas que surge em virtude de necessidades sociais básicas numa dada época histórica, possuindo caráter de relativa permanência e sendo identificável pelo valor de seus códigos de conduta, alguns dos quais são expressos sob a forma de leis. Nessa perspectiva as normas da matemática são elaboradas, justificadas e acrescentadas de maneira análoga às normas de outras instituições.

Sapere aude - Belo Horizonte, v. 7 - n. 14, p. 605-626, Jul./Dez. 2016 - ISSN: 2177-6342 
As leis das inferências matemáticas nos obrigam no mesmo sentido que outras leis na sociedade humana. Quando aprendemos a contar, na realidade o que aprendemos é a dizer "um", "dois", "três", "quatro" etc., sempre nessa ordem, numa prática repetitiva e sem fim, com impiedosa exatidão. Daí acharmos que o "dois" vem sempre depois do "um", inexoravelmente. Foi o mesmo tipo de inexorabilidade que permitiu a Euler deduzir a relação (8),

$$
\begin{aligned}
& e^{i x}+1=0, \\
& \text { a partir da }(7), \\
& e^{i \varphi}=\cos \varphi+i \operatorname{sen} \varphi .
\end{aligned}
$$

Depois dos gregos, e sem o conhecimento ou a aceitação deles, a prática repetitiva de que $\cos \pi=-1$, sen $\pi=0$, i x $0=0(!)$, aliada à das substituições através do sinal "=", é que possibilita os passos das inferências abaixo:

$$
\begin{aligned}
& \text { A) } \mathrm{e}^{\mathrm{i} \varphi}=\cos \varphi+i \operatorname{sen} \varphi \\
& \text { Ora, } \varphi=\pi \\
& \operatorname{Logo}, \mathrm{e}^{\mathrm{i} \pi}=\cos \pi+\mathrm{isen} \pi \\
& \text { B) } \mathrm{e}^{\mathrm{i} \pi}=\cos \pi+\mathrm{isen} \pi \\
& \text { Ora, } \cos \pi=-1 \\
& \operatorname{sen} \pi=0 \\
& \operatorname{Logo}, \mathrm{e}^{\mathrm{i} \pi}=-1+(\mathrm{i} \times 0)=-1+0=-1
\end{aligned}
$$

Nessa perspectiva, portanto, a necessidade e objetividade das relações matemáticas se tornam explicáveis através duma visada antropológica. É a concordância dos homens sobre a prova que fundamenta as matemáticas - e tal concordância é um fato contingente.

Não estaríamos, porém, caindo no mais completo relativismo, ao adotar tal concepção? Se estivéssemos postulando a existência de um referencial "exterior", através do qual seja possível avaliar a correção de uma determinada prática, a resposta seria afirmativa. Através de denominações como 'verdade objetiva', 'necessidade', 'objetividade' etc., expressamos contemporaneamente o nosso anseio por esse referencial absoluto e o perigoso relativismo que sua rejeição implicaria. Postulando, entretanto, nossa própria prática social como referencial de avaliação, a resposta à mesma questão é negativa. Cada sistema social estabelece seus próprios critérios de necessidade e julga a si próprio e a outros sistemas a partir desses mesmos critérios. Assim, só é possível avaliar um conjunto de práticas sociais através de outro conjunto também de 
Artigo: Aspectos da história do número $\pi$ na perspectiva duma filosofia da matemática de inspiração wittgensteiniana

práticas sociais. No caso específico dos diversos momentos da história das matemáticas, cada um deles constitui um sistema de provas que postula seus próprios padrões e julga outros sistemas de conformidade com tais padrões. Temos, pois, uma nova forma de conceber a necessidade, agora como socialmente definida: ela ainda existe, mas sob uma roupagem radicalmente diversa daquela do platonismo. E a acusação de relativismo não se coloca do mesmo modo, porque o próprio ato de fazer uma tal acusação já pressupõe a existência de um referencial absoluto, coisa que foi rejeitada nessa perspectiva.

Em síntese: só podemos avaliar a partir de um ponto de vista; o ponto de vista a que sempre recorremos é o da nossa própria prática social; esta última, circularmente, postula a si própria; não havendo prática social absoluta, não haverá também um referencial absoluto; em contrapartida, não haverá relativismo no sentido tradicional do termo - a necessidade e a contingência adquirem formas mais adequadas para a compreensão do homem e seus processos sociais.

Para reforçar essa tese, vejamos como é possível reinterpretar a avaliação que os historiadores contemporâneos da matemática fazem de alguns dos resultados que os modernos obtiveram sobre número $\pi$. Ao discutir o problema da quadratura do círculo, por exemplo, Boyer afirma: "essencialmente já Euclides sabia que as raízes de $\mathrm{ax}^{2}+\mathrm{bx}+\mathrm{c}=0$ onde a, b, c, são múltiplos inteiros de um dado comprimento, podem ser construídos geometricamente com régua e compasso" (BOYER, 1974, p. 406, grifos nossos). Mais adiante, ao referir-se à demonstração de que $\pi$ não é algébrico, ele conclui: "aqui, finalmente, estava a resposta ao problema clássico da quadratura do círculo. Para que a quadratura do círculo fosse possível com os instrumentos euclidianos, o número $\pi$ teria que ser raiz de uma equação algébrica com uma raiz exprimível por raízes quadradas" (p. 407, grifo nosso). Sabemos que um dos algebrizadores da geometria foi Descartes. Recorrendo a novos métodos, ele mostrou que o problema algébrico envolvendo a resolução de equações do primeiro grau equivalia a problemas geométricos com solução através apenas de uma régua; problemas algébricos envolvendo a resolução de equações do segundo grau equivaliam a problemas geométricos com solução através de régua e compasso; problemas algébricos envolvendo a resolução de equações irredutíveis de terceiro grau ou mais não equivaliam a problemas geométricos com soluções através apenas de régua e compasso (DANTZIG, 1970, p. 172). Em que pese o fato de desconhecermos o papel exato desempenhado 
pela álgebra na Matemática Grega, fica claro que a afirmação de Boyer, relativa ao fato de Euclides "essencialmente" já saber que a resolução geométrica da equação do segundo grau envolve régua e compasso, só faz sentido da perspectiva em que esse historiador se encontra. Dificilmente Euclides poderia dar aval a tal afirmação, pois ela depende de um sistema de avaliações do qual ele não participou.

Com relação ao tratamento dado por Euler no estudo das séries infinitas, Cajori diz:

Ele avisa seus leitores ocasionalmente contra o uso de séries divergentes, mas ele próprio é muito descuidado. O tratamento rígido a que as séries infinitas são agora submetidas era então insuspeitado. Não existiam noções claras com relação àquilo que constitui uma série convergente. Nem G. W. Leibniz nem Jakob e Johann Bernoulli sustentaram qualquer dúvida séria sobre a correção da expressão $1 / 2=1-1+1-1+1$ $1+1$ (...). Guido Grandi (1671 - 1742) de Pisa foi tão longe a ponto de concluir, a partir disso, que $1 / 2=0+0+0[\ldots]$. No tratamento de séries, Leibniz avançou um método metafísico de prova que dominou as mentes dos Bernoullis mais velhos e mesmo de Euler. A tendência daquele raciocínio era justificar resultados que parecem altamente absurdos aos seguidores de Abel e Cauchy. A frouxidão no tratamento pode ser melhor observada a partir de exemplos. [...] Euler não hesita em escrever $1-3+5-7 \ldots .=0$, e ninguém objetou a tais resultados, exceto Nicolaus Bernoulli, o sobrinho de Johann e Jakob. Por estranho que pareça, Euler finalmente conseguiu converter Nicolaus Bernoulli de suas próprias concepções errôneas. (CAJORI, 1919, p. 237-238).

Essa citação mostra com uma clareza cristalina a influência do ponto de vista do historiador na avaliação dos resultados matemáticos de épocas anteriores à sua própria. Os matemáticos modernos acreditavam nos resultados citados exatamente porque os métodos de que dispunham autorizavam aqueles mesmos resultados. Havia um certo consenso sobre eles, a um tal ponto que Euler pôde convencer Nicolaus Bernoulli a respeito de provas hoje consideradas errôneas. Não há nada de estranho nisso, a não ser que pensemos que, agindo assim, eles estavam encobrindo uma realidade pré-existente. De fato, só foi possível concluir que seus procedimentos eram inconvenientes quando se inventaram novos métodos, através da reinterpretação das regras para tratamento das séries divergentes. Referindo-se ao mesmo período, Tobias Dantzig afirma:

Os métodos improvisados, inaugurados por Kepler e Cavalieri, tiveram continuação, apenas com um pretenso refinamento de Newton, e Leibniz, de Wallis, o inventor do símbolo da infinidade, dos quatro Bernoulli, de Euler, de d'Alembert. Eles tratavam com os infinitésimos como sendo fixos ou variáveis, quando as exigências do problema; manipulavam aleatoriamente as sequências infinitas; faziam malabarismos com os limites; tratavam séries divergentes como se estas obedecessem a todas as regras de convergência. Definiam seus termos vagamente e usavam seus métodos livremente e a lógica de seus argumentos era construída de modo a adaptar-se aos ditames de sua intuição. Em suma, romperam todas as leis de rigor e de decoro matemático. [...] Veio

Sapere aude - Belo Horizonte, v. 7 - n. 14, p. 605-626, Jul./Dez. 2016 - ISSN: 2177-6342 
Artigo: Aspectos da história do número $\pi$ na perspectiva duma filosofia da matemática de inspiração wittgensteiniana

então período crítico: Abel e Jacobi, Gauss, Cauchy e Weierstrass, e finalmente Dedekind e Cantor, sujeitaram toda a estrutura a uma análise profunda, eliminando o vago e o ambíguo. E qual foi o resultado líquido dessa reconstrução? Bem, ele condenou a lógica dos pioneiros, mas justificou sua fé. (DANTZIG, 1970, p. 120; 125, grifos nossos).

As expressões grifadas são mais que significativas e dispensam comentários. A observação final de Dantzig, contudo, é uma peça rara, do ponto de vista da concepção wittgensteiniana: os antepassados pioneiros ficam com a fé; nós contemporâneos ficamos com a lógica. O que nos autoriza a dizer isso senão o nosso próprio sistema contemporâneo de provas? O que postula nossa lógica a não ser a si própria, quando se refere à fé dos antepassados?

Ainda que superficiais, as considerações acima permitem que formulemos algumas conclusões, que ficam como sugestões para um estudo posterior, mais aprofundado. Primeiramente, ao considerar as inferências matemáticas como contingentes, Wittgenstein nos proporciona uma concepção antropológica dessa ciência. Aquilo que se considera teoricamente possível numa dada época é o que se tem condição técnica e prática de realizar. Dessa maneira, as elaborações matemáticas possíveis não estão fixadas de antemão num mundo transceleste: elas podem ser sempre ampliadas pela atividade criativa do homem. As matemáticas não se baseiam em conceitos e formas de argumentação que, uma vez estabelecidos, são verdadeiros para sempre. Ao contrário, elas constituem uma espécie de mosaico de invenções humanas, um mosaico que envolve técnicas de conceituação e processos de demonstração. Portanto, os conceitos matemáticos dependem dos modos de calcular através dos quais são definidos e tais modos de calcular dependem, em última instância, dos processos sociais de que fazem parte. "A maneira pela qual a fórmula significa", diz Wittgenstein (1956: I, 2, 3), "determina quais passos devem ser dados. Qual é o critério para a maneira pela qual a fórmula significa? Presumivelmente o modo pelo qual sempre a usamos, o modo pelo qual aprendemos a usá-la".

Em segundo lugar, a maneira pela qual interpretamos as mudanças de aplicação duma regra pode ser explicada como segue. Inicialmente, somos treinados a aplicar a fórmula conforme um dado procedimento. Em circunstâncias novas, mudamos os aspectos relevantes do procedimento anterior, mas continuamos a acreditar que estamos agindo como sempre, baseados na ideia de que o novo procedimento é uma extensão natural do anterior, que foi simplesmente "corrigido". Não há qualquer garantia epistemológica de que a inovação seja coerente com a

Sapere aude - Belo Horizonte, v. 7 - n. 14, p. 605-626, Jul./Dez. 2016 - ISSN: 2177-6342 
prática antiga. A verdadeira garantia está em que o grupo social considera estarmos corretos ao agirmos assim. "Coerente" torna-se sinônimo de "considerado consensualmente como extensão natural do procedimento precedente". É isso que dá a impressão de que existe "A" matemática, cuja história tem um caminho definido. Na realidade, estamos diante de várias matemáticas, cada qual com sua história particular, determinada pelo tipo de prática social do grupo que a utiliza. Os momentos cruciais dessas histórias particulares são aqueles em que, diante de uma questão considerada importante, alguém reinterpreta as regras, recriando conceitos e redimensionando a própria matemática do grupo. A reinterpretação, porém, não basta: é necessário que ela seja aceita pelo grupo como consistente.

Essa nova concepção das matemáticas tem como vantagem principal o seu direcionamento no sentido da prática social. Assim entendidas, as matemáticas nada mais são do que jogos de linguagem entre outros. E o importante aqui está na tentativa de mostrar como tal fato ocorre. Com efeito, já existem teorias que ligam as matemáticas à prática social. Chapelon, por exemplo, em 1948, dizia:

\begin{abstract}
A pressão das necessidades sociais eleva pouco a pouco ao nível de especulações científicas aquilo que primitivamente era apenas uma coleção de receitas empíricas. $\mathrm{O}$ desenvolvimento inicial das matemáticas é, pois condicionado pelas forças produtivas de uma sociedade em contínua transformação. Essa influência das forças produtivas ultrapassa o período inicial e domina toda a história das matemáticas. As particularidades do progresso matemático correspondem às particularidades do desenvolvimento social. (CHAPELON, 1948, p. 517-518).
\end{abstract}

Na mesma época, e numa perspectiva mais claramente marxista, Labérenne afirmava:

O marxismo não se contenta em nos dar a explicação da evolução histórica das matemáticas em função das condições técnicas, econômicas e sociais de que elas dependem, ele nos permite também analisar o próprio mecanismo do caminhar do pensamento científico por crises e sínteses sucessivas e orientar nossas pesquisas (LABÉRENNE, 1948, p. 386).

Apesar da justeza das afirmações dos autores citados, fica claro, pela leitura de seus textos, que eles não têm um modelo explicativo adequado para mostrar como se dá a evolução histórica das matemáticas. Falta-lhes justamente aquilo que a concepção wittgensteiniana oferece: uma teoria das inferências matemáticas como práticas sociais, uma compreensão da necessidade matemática como consenso grupal.

Sapere aude - Belo Horizonte, v. 7 - n. 14, p. 605-626, Jul./Dez. 2016 - ISSN: 2177-6342 
Artigo: Aspectos da história do número $\pi$ na perspectiva duma filosofia da matemática de inspiração wittgensteiniana

A grande desvantagem dessa nova concepção está também na sua tendência em centrar a explicação na prática social. Toda concepção que apresente essa característica pragmática acaba, mais cedo ou mais tarde, acusada de sociologismo ou de relativismo. Já tentamos mostrar que, quando não postulamos a existência de um referencial absoluto, a questão do relativismo não se coloca da mesma maneira. Parece-nos, inclusive, que a grande opção do pensamento contemporâneo está na busca de modelos explicativos do conhecimento que não postulem um referencial absoluto. Se estamos certos ou não, o tempo dirá. Esperamos, contudo, que essa dificuldade não afaste o leitor interessado de uma pesquisa mais acurada sobre o assunto.

Fazendo um balanço geral dessa nova concepção, acreditamos que ela apresente sobre as demais a vantagem de possuir uma abertura maior. Ela permite que busquemos a explicação das matemáticas "fora" delas. Com base nisso, podemos nos perguntar, exercendo um novo tipo de curiosidade, por que, por exemplo, a Academia de Paris resolveu não considerar soluções ao problema da quadratura antes que sua impossibilidade fosse demonstrada. Não estaríamos diante de um desejo emergente de vetar a solução do problema, em contraposição ao antigo e ardente desejo dos quadratores de todos os tempos? Até que ponto esse desejo se sobrepôs ao anterior e determinou o consenso acerca da impossibilidade da quadratura? É verdade que o historiador clássico da matemática não vê as coisas assim. Mas não estaríamos justamente no momento adequado para realizar a mudança de perspectiva aqui sugerida? O mínimo que faríamos seria libertar as matemáticas do jugo do idealismo platônico, que tanto tem disfarçado sua riqueza. Uma riqueza que só será percebida quando, seguindo a sugestão de Wittgenstein, formos capazes de conceber a possibilidade de uma civilização em Marte, a qual estaria extremamente preocupada com a fragilidade e a inconsistência do ser marciano. Para os matemáticos de uma tal sociedade, as melhores demonstrações seriam aquelas que levassem a contradições, pois constituiriam ilustrações dessa mesma fragilidade e inconsistência. Estaríamos assim diante de um jogo de linguagem inteiramente diverso do nosso.

Não é preciso ir tão longe, porém. Entre os hindus, Aryabhata, por volta de 499 d.C., escreveu um pequeno livro de matemática em forma de versos (!). Ali, de maneira poética, ele nos dá a seguinte solução para a regra de três: "multiplique-se o fruto pelo desejo e divida-se pela medida. O resultado será o fruto do desejo" (apud BOYER, 1974, p. 154, grifos nossos). Cabe a 
nós, unicamente a nós, a responsabilidade por encontrar a leitura mais adequada para entender essa mensagem, ao mesmo tempo tão antiga e tão atual.

\section{REFERÊNCIAS}

BLOOR, D. (1973). Wittgenstein and Mannheim on the Sociology of Mathematics. Stud. Hist. Phil. Sci. 4 (1973), n. 2.

BOYER, C. B. História da matemática. Tradução Elza F. Gomide. S. Paulo: Edgard Blucher Ltda; EDUSP, 1974.

CAJORI, F. A history of mathematics. N. York: The Macmillan Co, 1919.

CHAPELON, J. Mathématiques et développement social. Lionnais, 1948.

DANTZIG. T. Número: a linguagem da ciência. Rio de Janeiro: Zahar, 1970.

DUBREIL, P. L'Histoire des Nombers Mysterieux. Lionnais, 1948, p. 99-113.

LABÉRENNE, P. Les Mathématiques et le Marxisme. Lionnais ,1948, p. 378-88.

LIONNAIS, F. (Ed.). Les grands courants de la pensée mathématique. Cahiers du Sud,1948.

WITTGENSTEIN, L. Philosophical investigations. 2nd ed. Oxford: Basil Blackwell, 1958.

WITTGENSTEIN, L. Remarks on the Foundations of mathematics. Oxford: Basil Blackwell., 1956. 